\title{
Molecular Cloning, Promoter Analysis and Expression Profiles of the sox3 Gene in Japanese Flounder, Paralichthys olivaceus
}

\author{
Jinning Gao ${ }^{1,2,+}$, Peizhen $\mathrm{Li}^{2,+}$, Wei Zhang ${ }^{2}$, Zhigang Wang ${ }^{2}$, Xubo Wang ${ }^{2, *}$ and \\ Quanqi Zhang ${ }^{2, *}$
}

Received: 26 August 2015; Accepted: 13 November 2015; Published: 24 November 2015

Academic Editor: Jun Li

1 Center for Developmental Cardiology, Institute for Translational Medicine, College of Medicine,

Qingdao University, 38 Dengzhou Road, Qingdao 266021, China; gjn.1127@163.com

2 Key Laboratory of Marine Genetics and Breeding (MGB), Ministry of Education,

College of Marine Life Sciences, Ocean University of China, 5 Yushan Road, Qingdao 266003, China; peizhenlee@163.com (P.L.); 18366207357@163.com (W.Z.); zgwang@ouc.edu.cn (Z.W.)

* Correspondence: wangxubo@ouc.edu.cn (X.W.); qzhang@ouc.edu.cn (Q.Z.);

Tel./Fax: +86-532-8203-1806 (X.W. \& Q.Z.)

+ These authors contributed equally to this work.

\begin{abstract}
Sox3, which belongs to the SoxB1 subgroup, plays major roles in neural and gonadal development. In the present study, Japanese flounder Paralichthys olivaceus sox3 gene (Posox3) and its promoter sequence were isolated and characterized. The deduced PoSox 3 protein contained 298 amino acids with a characteristic HMG-box domain. Alignment and phylogenetic analyses indicated that PoSox3 shares highly identical sequence with Sox3 homologues from different species. The promoter region of Posox 3 has many potential transcription factor (TF) binding sites. The expression profiles of Posox 3 in different developmental stages and diverse adult tissues were analyzed by quantitative real-time RT-PCR (qRT-PCR). Posox $3 \mathrm{mRNA}$ was maternally inherited, and maintained at a considerably high expression level between the blastula stage and the hatching stage during embryonic development. Posox 3 was abundantly expressed in the adult brain and showed sexually dimorphic expression pattern. In situ hybridization (ISH) was carried out to investigate the cellular distribution of Posox 3 in the ovary, and results showed the uniform distribution of Posox 3 throughout the cytoplasm of oogonia and stage I-III oocytes. These results indicate that Posox3 has potentially vital roles in embryonic and neural development and may be involved in the oogenesis process. Our work provides a fundamental understanding of the structure and potential functions of Sox3 in Paralichthys olivaceus.
\end{abstract}

Keywords: Japanese flounder (Paralichthys olivaceus); sox3; promoter analysis; sexually dimorphic expression

\section{Introduction}

The Sox protein family, which participates in diverse developmental events, has been classified into group A-J based on the HMG domain phylogeny [1]. The molecules in the SoxB1 subgroup, including Sox1, Sox 2 and Sox3, share more than $90 \%$ amino acid identity in their characteristic HMG box domains. SoxB1 proteins are indicated to have overlapping properties and tend to function interactively and redundantly [2-4]. Significantly, SoxB1 genes continue to be expressed in the developing central nervous system (CNS) and can maintain the neural progenitor identity [5-8]. Nevertheless, their functions are not strictly redundant and each of them possesses distinct roles 
during embryonic development and in cell fate determination. Among them, Sox2 is well known as a pluripotency factor that cooperates with Oct4 and Nanog in regulating the pluripotent state of embryonic stem cells $[9,10]$. Sox 1 appears to play a direct role in promoting neural determination and differentiation [11]. Sox3, which is considered to be the ancestral precursor of Sry, is required for sex differentiation and gonadal development $[12,13]$.

Fish are the most diverse and species-rich group of vertebrates, serving as an evolutionary link between invertebrate and higher vertebrates. So far, few studies have been reported on the teleost sox3 gene. Diverse expression profiles of soxB1 during early embryo development have been observed in zebrafish when compared with those in amniotes, but their overall functions in neural development may be conserved among vertebrate species [14]. Specifically, gain- and loss-of-function experiments in zebrafish elucidate the role of Sox3 both in neural fate determination and differentiation [15]. In grouper Epinephelus coioides, dynamic expression pattern of Sox 3 in the gonad confirms its potential role in oogenesis and germ cell differentiation [16]. In catfish Clarias batrachus, results suggest a possible role for Sox3 in the regulation of testicular development [17]. Recently, Takehana, et al. [18] have shown that Sox3 initiates testicular differentiation in Oryzias dancena.

A promoter is a vital region containing various elements and TF binding sites that can regulate gene expression. For the past ten years, Milena Stevanovic's team concentrated on the functional characterization of the human SOX3 promoter [19]; they have conducted experiments to demonstrate that TFs, such as NF-Y, TGIF, PBX1 and MEIS1, and CREB, are key regulators of SOX3 expression, either in a positive or negative way [20-23]. Also, it has been reported that a small ubiquitin-like modifier (SUMO) represses transcriptional activity of SOX3 at the posttranscriptional level [24]. However, little is known about the transcriptional regulation of sox3 in lower vertebrate, especially in the marine fish.

The Japanese flounder, Paralichthys olivaceus, is widely distributed along the coastal shelf of Northeast Asia and is one of the most promising and commercially important flatfish species in the region. Investigation on the soxB1 genes is of interest and significant benefit for further study. We have previously isolated and characterized the sox 1 and sox 2 genes in P. olivaceus, which are predominately expressed at the early development stages and in the brain tissue $[25,26]$. Moreover, we demonstrated that two co-orthologs of sox1 (Posox1a and Posox1b) exist in the flounder genome generated by gene duplication. However, the expression of Posox2 may not be regulated through the CpG sites in its regulatory region. Thus, elucidating the role of Posox3 is necessary to form a comprehensive understanding of soxB1 genes in P. olivaceus. For these purposes, here we describe the molecular characterization of Japanese flounder sox3, its quantified expression profiles during early embryo development and in diverse adult tissues, and analyses of its cellular distribution in the ovary. In addition, analysis of potential regulatory motifs in the upstream region was conducted to facilitate further functional studies in this species.

\section{Results}

\subsection{Molecular Characterization of Posox3}

\subsubsection{Cloning and Sequence Analysis of Posox3}

Using degenerate primers and RACE strategy, we cloned Posox3 from the brain tissue of Japanese flounder. All obtained fragments were assembled to yield a cDNA with $208 \mathrm{bp}$ of $5^{\prime}$ UTR, $737 \mathrm{bp}$ of $3^{\prime}$ UTR and $897 \mathrm{bp}$ of the entire open reading frame (ORF). A putative polyadenylation signal (ATTAAA) was found $10 \mathrm{bp}$ upstream of the poly (A) tail (GenBank accession number: KR108248) (Figure 1). The predicted PoSox3 amino acid sequence was 298 amino acids with an estimated molecular mass (MM) of $33.22 \mathrm{kDa}$ and an estimated isoelectric point (IP) of 9.66. Similarly with other Sox proteins, PoSox3 had the characteristic HMG-box DNA binding domain (72 aa), located on the amino acids 32 to 103, and the SOX transcription factor (SOXp) domain (80 aa) at 102-181 aa (Figure 1). 


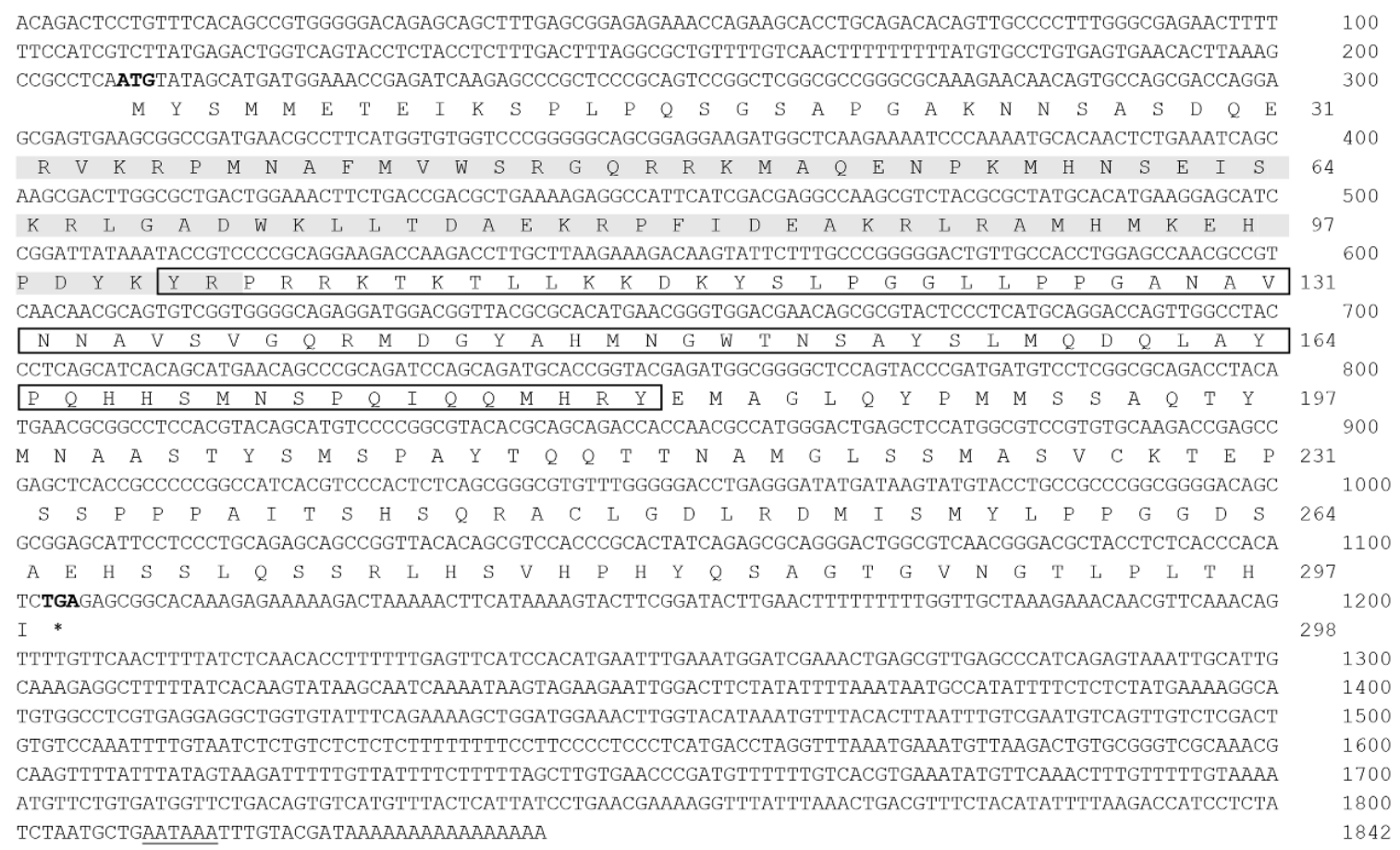

Figure 1. The nucleotide and deduced amino acid sequences of Posox3. The HMG (high mobility group) box domain is shaded in gray and the SOXp (SOX transcription factor) domain is boxed. The start and stop codons are bold-typed and the stop codon is represented as asterisk $\left(^{*}\right)$. The polyadenylation signal (AATAAA) is indicated with single line. Nucleotides and amino acids are numbered at the right end of the lines.

\subsubsection{Protein Alignment and Phylogenetic Analysis of PoSox3}

The amino acid sequence of PoSox3 was compared to known Sox3 proteins from other ray-finned fish and higher vertebrates. The overall identities between PoSox 3 and other Sox 3 were extremely high, from $75.5 \%$ with $H$. sapiens Sox 3 to $97.7 \%$ with X. maculatus Sox3 (Figure S1). The alignment confirmed the presence of the conserved HMG-box domain within PoSox3, which is the characteristic of Sox proteins (Figure 2A). To gain insight of the evolutionary relationship between PoSox 3 identified in this study and the SoxB molecules of other vertebrate, a phylogenetic tree was constructed (Figure 2B), which showed two distinct clades representing SoxB1 and SoxB2 subgroups. The clade of SoxB1 consisted of three subclades, namely Sox1, Sox2 subclades and a Sox3 subclade containing PoSox3. PoSox 3 then clustered with its homologues in teleost. Moreover, the molecular relationship indicated by this tree was consistent with the taxonomic classification of these species.

A

Paralichthys olivaceus Sox3

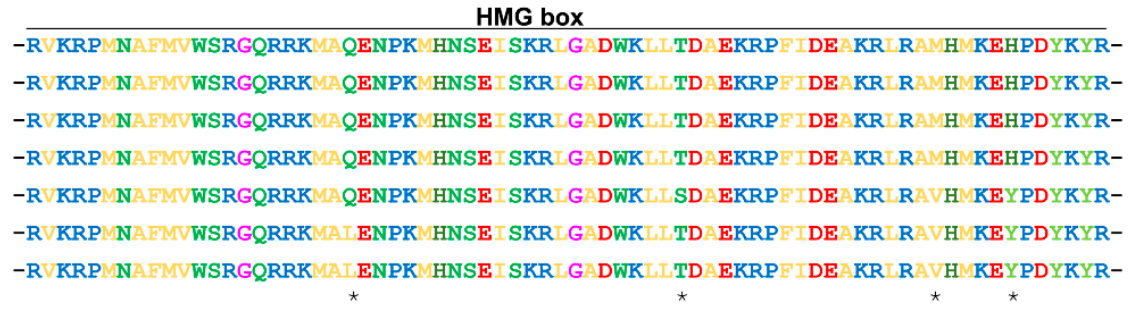

Figure 2. Cont. 


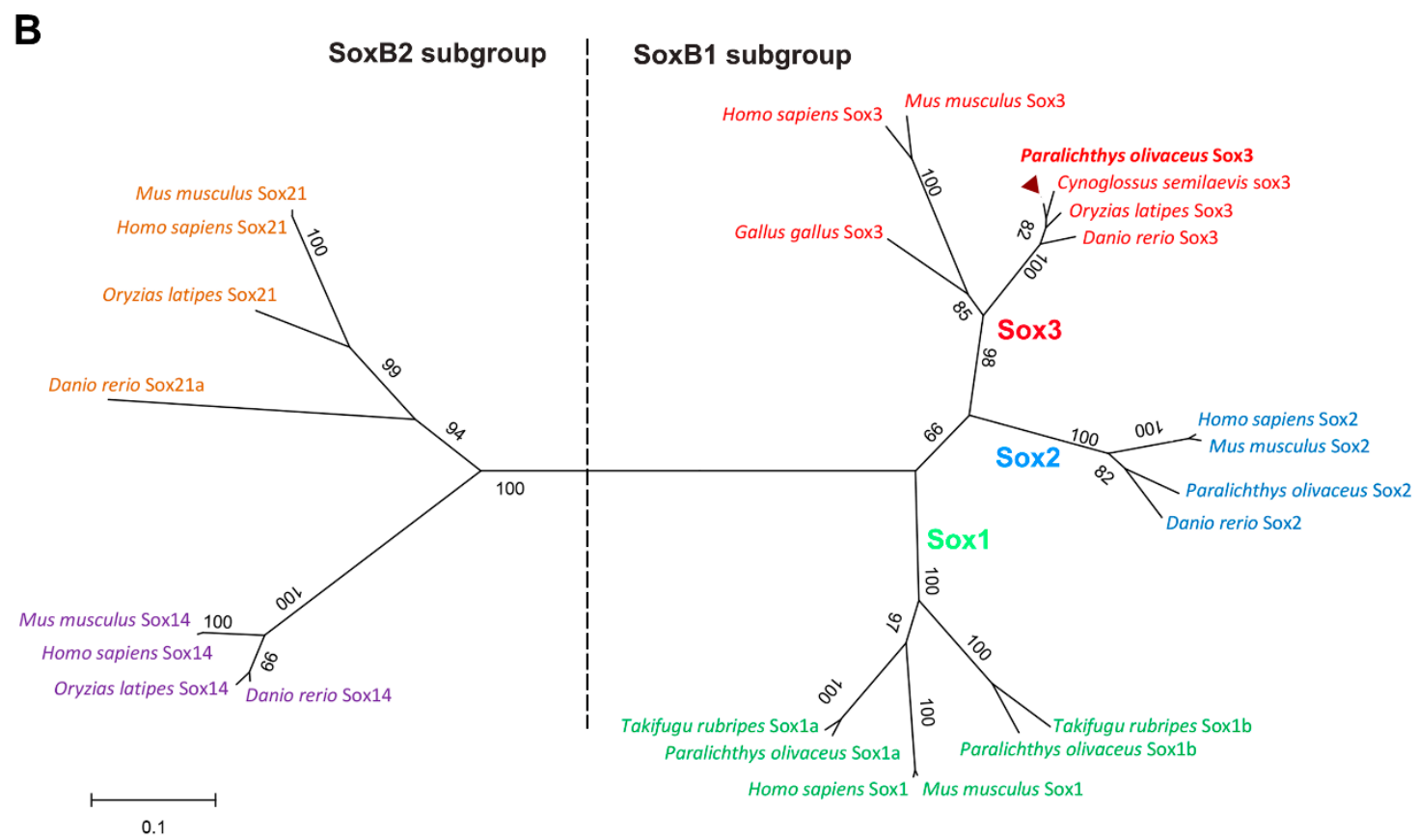

Figure 2. PoSox 3 amino acids alignment and phylogeny. (A) Alignment of HMG-box domain of PoSox3 with those of other vertebrate orthologues. Different amino acid residues between fish and tetrapods are indicated with asterisks; (B) Phylogenetic relationships of PoSox3 and SoxB proteins from other representative species. The Neighbor-Joining tree was constructed by MEGA (version 6.06) with 1000 bootstrapping based on the full-length amino acids sequences. The sequences were obtained with the following GenBank accession numbers: Homo sapiens: NP_005977.2 for Sox1; NP_003097.1 for Sox2; NP_005625.2 for Sox3; NP_004180.1 for Sox14; NP_009015.1 for Sox21; Mus musculus: NP_033259.2 for Sox1; NP_035573.3 for Sox2; NP_033263.2 for Sox3; NP_035570.1 for Sox14; NP_808421.1 for Sox21; Gallus gallus: NP_989526.1 for Sox3; Danio rerio: NP_998283.1 for Sox2; NP_001001811.2 for Sox3; NP_001032769.1 for Sox14; NP_571361.1 for Sox21a; Oryzias latipes: NP_001098234.1 for Sox3; NP_001158344.1 for Sox14; NP_001158346.1 for Sox21; Cynoglossus semilaevis: XP_008324981.1 for Sox3; Paralichthys olivaceus: KR108250 for Sox1a; KR108247 for Sox1b; KF709692 for Sox2; KR108248 for Sox3 (solid triangle); Takifugu rubripes: XP_003961796.1 for Sox1a; XP_003977952.1 for Sox1b. Distinct clades were indicated with different colors.

\subsubsection{Genomic Organization and Analysis of Posox3}

Comparison of the genomic (GenBank accession number: KT314157) and cDNA sequences showed that Posox3 was a one-exon gene. Numerous putative binding sites for TFs involved in cellular proliferation and differentiation as well as ubiquitous TFs were revealed by online software MatInspector in the $\sim 2.2 \mathrm{~kb}$ region upstream of the start codon (Figure 3A, Table S1). Several Sox/sry-sex/testis-determining and related HMG box factors, including Sox5, Sox6, and Sox3 itself, were identified. Some of these TFs, such as brain specific homebox (BSX), neurogenin 1 and 3 (NEUROG), TG-interacting homeodomain factor (TGIF), and myelin transcription factor 1 (MyT1), were involved in neurogenesis. Furthermore, other development related factors including POU domain, class 5, transcription factor1 (Oct4), pre-B-cell leukemia homeobox 3 (PBX), myeloid ecotropic viral integration site 1 homologue (MEIS1) and cAMP-responsive element binding protein (CREB) were identified. Ubiquitous binding sites for activator protein 1 (AP1), nuclear factor Y (NF-Y), stimulating protein 1 (Sp1), and upstream stimulating factor (USF) were also found. Unlike the mammalian Sox3 [27], the canonical TATA box was not found in the promoter region of Posox3. Nevertheless, at least $100 \mathrm{bp}$-long evolutionary conserved regulatory region was revealed by the comparative genomic analysis of fish sox3 orthologous promoters (Figure 3B). 
A

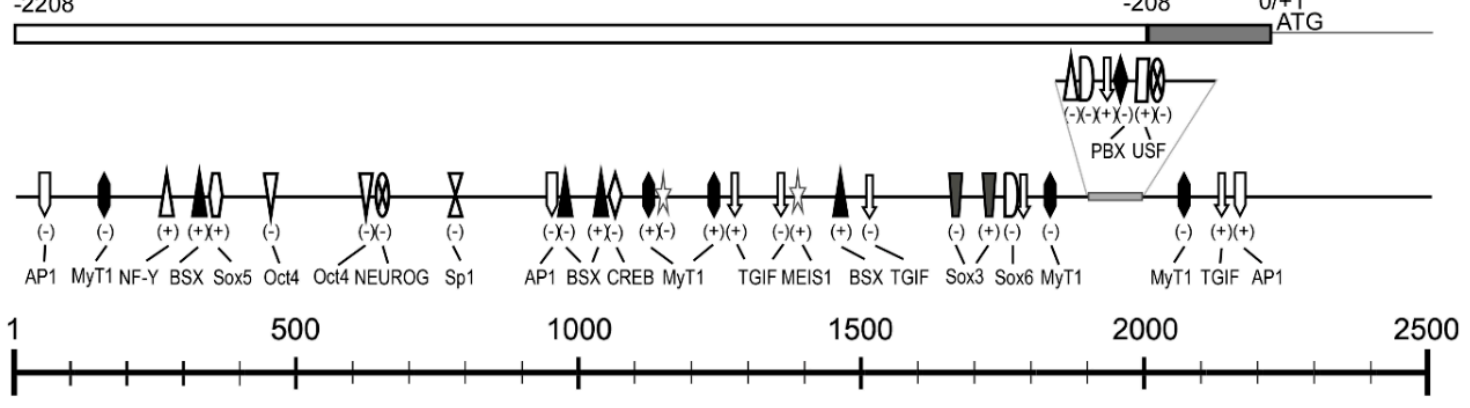

AP1: Activator protein 1; BSX: Brain specific homeobox; CREB: CAMP-responsive element binding proteins; MEIS1: Meis homeobox 1; MyT1: MyT1 zinc finger transcription factor involved in primary neurogenesis; NEUROG: Neurogenin 1 and 3 (ngn1/3) binding sites; NF-Y: Nuclear factor $Y$ (Y-box binding factor); Oct4: POU domain, class 5, transcription factor 1; PBX: Pre-B-cell leukemia homeobox 3, PBX - MEIS complexes; Sox3: SRY (sex determining region Y)-box 3; Sox5: SRY (sex determining region Y)-box 5; Sox6: SRY (sex determining region Y)-box 6; Sp1: Stimulating protein 1, ubiquitous zinc finger transcription factor; TGIF: TG-interacting factor belonging to TALE class of homeodomain factors; USF: Upstream stimulating factor.

B

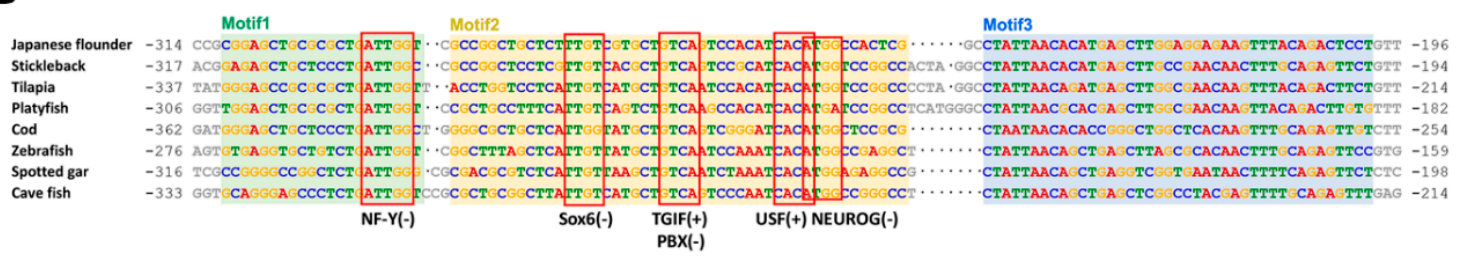

Figure 3. Bioinformatic analyses of the promoter sequence of Posox3. (A) The potential TF binding sites were drawn on the schematic diagram with their corresponding locations within the promoter of Posox3. The scale is shown above and the detailed information are supplied at the bottom. The plus-minus symbols indicate the strand with which the TFs bind. The gray block represents the conserved upstream region among different fish species. The details for TFs see in Table S1; (B) Consensus motif regions in the $5^{\prime}$ upstream sequences of different fish sox 3 orthologs analyzed by software MEME and Dialign. The GenBank accession number of Japanese flounder (Paralichthys olivaceus) sox3 was KT314157. Other sox3 5'-flanking sequences were searched from Ensembl [28] and their gene IDs were as follows: Stickleback (Gasterosteus aculeatus) sox3: ENSGACG00000017181; Tilapia (Oreochromis niloticus) sox3: ENSONIG00000020861; Platyfish (Xiphophorus maculatus) sox3: ENSXMAG00000019515; Cod (Gadus morhua) sox3: ENSGMOG00000020190; Zebrafish (Danio rerio) sox3: ENSDARG00000053569; Spotted gar (Lepisosteus oculatus) sox3: ENSLOCG00000017493; Cave fish (Astyanax mexicanus) sox3: ENSAMXG00000025368. The potential TF (NF-Y, Sox6, TGIF/PBX, USF, and NEUROG) binding sites within the conserved motifs are boxed and indicated above the aligned sequences.

\subsection{Expression Profiles of Posox3 during Embryonic Development and in the Larval and Juveniles}

To evaluate the temporal expression levels of Posox3 during early embryo development as well as in the larvae and juveniles, we conducted qRT-PCR analysis. Posox 3 mRNA could already be detected in the unfertilized egg. With the early embryonic cleavage and subsequent development proceeding, the amount of transcript remained stable at a low level until the morula stage, strongly increased at the high-blastula stage, then reached the peak at the early gastrula stage. The Posox 3 transcript was greatly diminished after hatching, and gradually decreased from 1 day post-hatching (dph) to $45 \mathrm{dph}$. In general, Posox 3 was highly expressed from the high-blastula stage to the hatching stage, and had low expression levels at the other examined stages (Figure 4). 


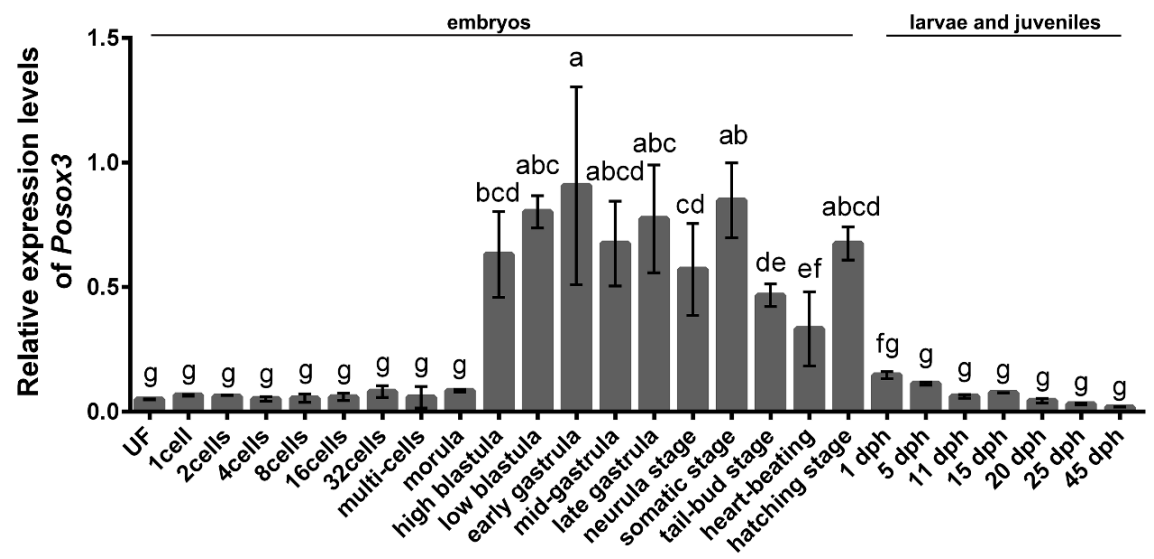

Figure 4. qRT-PCR analysis of Posox3 during embryonic development and in larvae and juveniles. Relative mRNA level is shown as mean $\pm \operatorname{SEM}(n=3)$. The relative expression variance is given as ratio (the amounts of Posox $3 \mathrm{mRNA} /$ reference genes). Different letters indicate significant difference $(p<0.05)$. UN, unfertilized egg; dph, days post-hatching.

\subsection{Expression Profiles of Posox3 in Different Tissues and in Adult Brain}

To examine the tissue distribution of Posox3, we performed qRT-PCR analysis using RNA from various tissues of 1.5-year-old adult fish. The results showed that Posox3 was highly expressed in ovary, gill and brain, low in muscle and testis, and almost undetectable in heart, liver, spleen, kidney and intestine tissues (Figure 5A). The expression of sox3 in gill tissue in addition to gonads and brain has also been found in other fish species [18]. Notably, Posox3 showed a sexually dimorphic expression pattern that the transcript was abundant in ovary but deficient in testis.

The Posox 3 transcript was highly expressed in the brain, suggesting its potential role in neural development. To acquire further information, we then analyzed its expression profiles among five different parts of the whole brain. Telencephalon and diencephalon showed high expression levels of the Posox 3 mRNA transcript, while decreasing levels were observed in the mesencephalon, macromyelon, and epencephalon (Figure 5B).

A

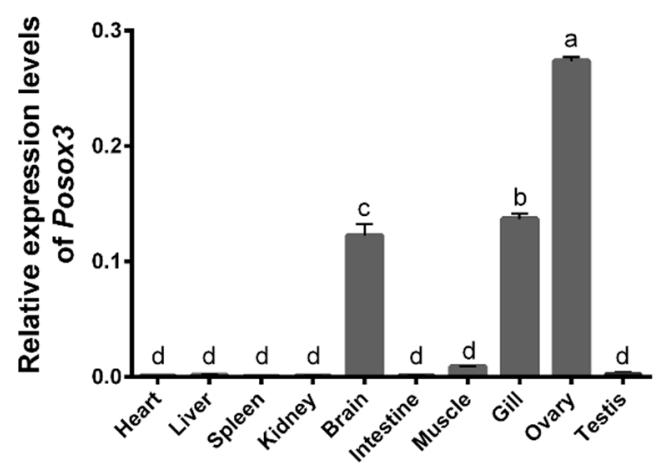

B

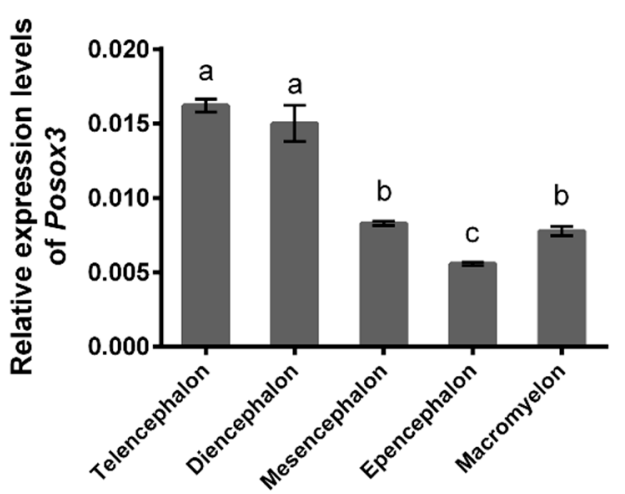

Figure 5. qRT-PCR analysis of Posox 3 in different adult tissues (A) and in different parts of adult brain (B). Relative mRNA level is shown as mean $\pm \operatorname{SEM}(n=3)$. The relative expression variance is given as ratio (the amounts of Posox $3 \mathrm{mRNA} /$ reference genes). Different letters indicate significant difference $(p<0.05)$. 


\subsection{In Situ Hybridization}

To elucidate localization of Posox 3 mRNA at the cellular level, we carried out in situ hybridization on paraffin-embedded ovary sections of Japanese flounder. The ovary section for ISH is composed of a small amount of oogonia, numbers of oocytes at different development stages including stage I (small), stage II (previtellogenic) and stage III (vitellogenic), as well as somatic follicle cells (Figure 6C). ISH revealed that Posox3 RNA was exclusively restricted to the germ cells, and no signal was detected in the surrounding somatic follicle cells. Moreover, Posox3 RNA was expressed throughout oogenesis and showed uniform distribution throughout the cytoplasm of oogonia and stage I-III oocytes (Figure 6A). However, no signal was observed in the control experiment using sense probes of Posox3 (Figure 6B).
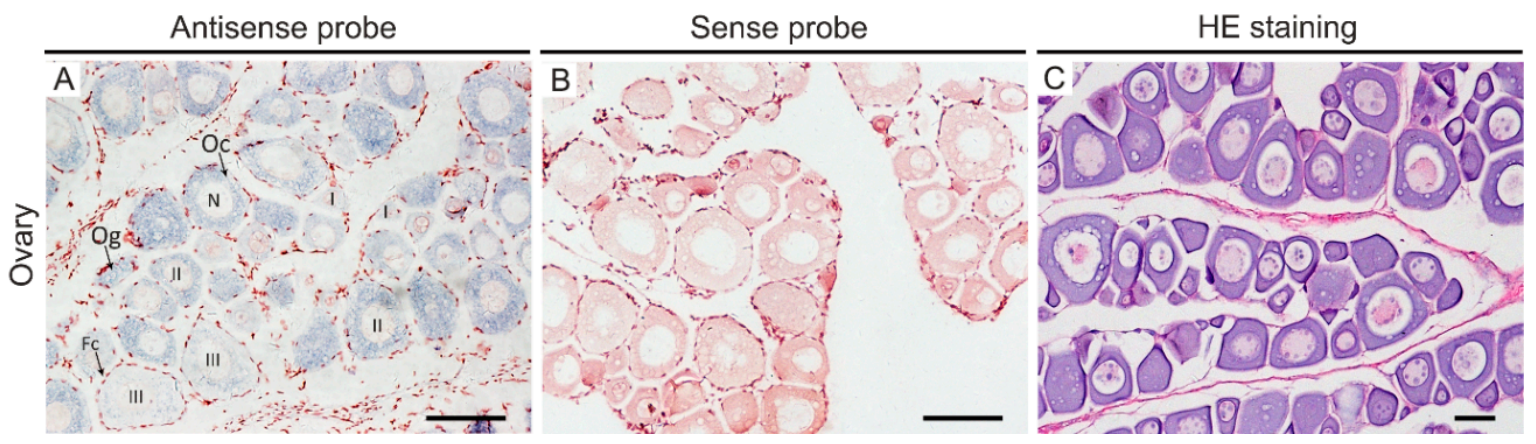

Figure 6. Spatiotemporal expression pattern of Posox3 mRNA in the ovary of adult Japanese flounder. In situ hybridization was performed on paraffin-embedded tissues with a DIG-labeled Posox3 antisense probe (A) or a sense probe as a control (B). The positive signals are stained with blue, whereas the negative control is not stained. HE staining in the ovary $(\mathrm{C})$, counterpart to A. In ovary, the Posox3 mRNA is widely distributed in the cytoplasm of different stages oocytes and highly expressed in stage II oocytes. Fc, follicle cells; N, nucleus; Oc, oocytes; Og, oogonia; I-III, oocyte stages. Scale bar, $100 \mu \mathrm{m}$.

\section{Discussion}

\subsection{Posox3 Is the Homolog of Mammalian Sox3}

In this study, we isolated and characterized the complete sequence of sox3 as well as its promoter region from a flatfish, Japanese flounder P. olivaceus. We conclude that Posox 3 encodes the Japanese flounder Sox 3 and is homologous to the mammalian Sox3 for the following reasons. Firstly, Posox3 is a one-exon gene. This is coincident with other reported SOX3/Sox3 genes [29,30]. Moreover, along with our previously studies [25,26], P. olivaceus soxB1 genes (Posox1a/b, Posox2, and Posox3) are all composed of a single exon, which is the conserved characteristic of the vertebrate SoxB1 subgroup [1]. Secondly, the HMG-box domain of PoSox3 contained the nine specificity amino acids, RPMNAFWVW (positions, 4-12), which appears to be the most reliable signature of the Sox family [1]. Further, alignment of the predicted PoSox3 with other Sox3 proteins from various species shows overall high identity $(75.5 \%-97.7 \%)$, especially within the conserved HMG-box domain and its C-proximal region. These suggest that the Sox3 protein may be structurally conserved during vertebrate evolution. Finally, on a phylogenetic tree, the putative PoSox 3 is firstly clustered with other fish Sox3 proteins, coinciding with the separation between fish and tetrapod linages, then clustered with Sox 2 and Sox 1 proteins to form the SoxB1 clade. Taken together, these results indicate that the described Posox3 is the ortholog of mammalian Sox3. 


\subsection{The Potential TFs in Regulating Posox3 Expression}

Given the recognized importance of Sox3 in the regulation of embryonic development and in the determination of cell fate, characterization of the promoter sequence and identification of the molecular mechanism will contribute a better understanding to the regulation of its expression and function. Here, we analyze the $2000 \mathrm{bp} 5^{\prime}$ upstream sequence of Japanese flounder sox 3 through bioinformatics software to identify a number of putative TF binding sites. The TFs, including Sox3, Sox5, Sox6, Oct4, BSX, NEUROG, MyT1, TGIF, CREB, PBX, MEIS1, NF-Y, Sp1, AP1 and USF, may be involved in the regulation of Posox 3 expression and function.

Many transcription factors, including Sox factors, have been reported to have autoregulatory regions, where the protein can directly bind to or mediate with specific partners to achieve autoregulation [31-33]. Further, ChIP-seq analyses have indicated that Sox3 is one of the small subset of SOX3 direct target genes which require SOX3 for normal expression in the neural progenitors [34]. Interestingly, two binding sites for Sox 3 itself are found in the Posox3 promoter region, suggesting the potential mechanism of autoregulation.

Different from the consensus co-factors-binding site for PBX/MEIS, which has been demonstrated to participate in positively regulating human SOX3 gene expression by direct interaction [23], we identified separately located PBX and MEIS1 in the promoter region of Posox3. This is not surprising, for we have found binding sites for Oct4 in the Japanese flounder Nanog gene promoter, but not the mammalian composite Oct-Sox element in our previous study [35]. Moreover, heterologous DNA often functions similarly in organisms even if they share little regulatory sequence similarities (e.g., human DNA in fish) [36]. This may suggest regulatory sequence evolution and potential conservative functions from fish to mammals.

Oct4, a POU domain transcription factor, is critically involved in the stem cell self-renewal and pluripotency maintenance. It may interact with Sox3 to keep neural cells undifferentiated as Sox3 is found expressed in self-renewing neural progenitors [7,34,37]. Ubiquitous TFs, such as USF, Sp1 and NF-Y, which play important roles in diverse cellular processes, have been demonstrated to regulate the expression of several members of Sox gene family $[19,20,38]$. Our first step of promoter analysis was based on computational prediction, and whether these factors play conserved roles in regulating Posox3 expression needs verification. Still, the current results will provide fundamental information for further investigation on the transcriptional regulation mechanism and functional analysis of Posox3.

\subsection{Posox3 May Be Involved in the Regulation of Embryogenesis, Neural and Ovarian Development}

So far, few studies have reported the temporal expression profiles of sox3 during early embryogenesis in fish. The embryonic expression of Posox3 RNA is in general coincident with those that have been observed in red-spotted grouper and zebrafish, but different from annual killfish $[14,39,40]$. In our study, Posox 3 is maternally inherited, sustained at a low level until morula stage, then sharply increases from blastula stage on when zygotic transcription begins, and this high expression level persists until the hatching stage. Minor difference exists after hatching, and the transcript declines dramatically to a low level in Japanese flounder but is still highly expressed in red-spotted grouper [39]. Differently from Posox1a/b and Posox2, which are highly expressed at a certain stage (the neurula stage and the gastrula stage, respectively) $[25,26]$, the Posox3 transcript is abundant for a period of time during embryogenesis. It is important that germ layer differentiation, histogenesis and organogenesis occur during embryonic development. Our observation supports the speculation that a steady level of Posox 3 is associated with embryogenesis.

Sox3 is critical for neural development in vertebrates [4,14,41,42], and Sox3 deficient mice have defects in CNS midline structures [43]. In zebrafish, knockdown of Sox3 reduces the size of the CNS and subsequently inhibits some aspects of neurogenesis [15]. In addition, Sox3 plays an important role in maintaining neural progenitors residing in the telencephalic stem cell 
niches $[7,8,44]$. Tissue distribution analysis shows that Posox3 is highly expressed in brain tissue, especially abundantly in the telencephalon region, which suggests its potential vital role in the CNS.

In addition to the neural tissue, Sox 3 is also expressed in the gonadal tissue. In mouse, Sox3 has been demonstrated to be important for oocyte development, testis differentiation as well as gametogenesis [12]. However, in species-rich fish, diverse expression profiles reveal their distinct roles, mainly functioning either in testicular or in ovarian development. In protogynous hermaphrodite fish Epinephelus coioides, Ecsox3 has been suggested to have a more important role in oogenesis than in spermatogenesis, whereas sox3 is expressed highly in testis and involved in the development of testis more than ovary in protandrous hermaphrodite fish Acanthopagrus schlegeli $[16,45]$. In Clarias batrachus, sox3 shows a possible role in the regulation of testicular development [17]. In our present study, Posox3 is more highly expressed in the ovary than in the testis. This expression pattern is in agreement with what has been observed in red-spotted grouper, but in contrast to black porgy and catfish $[16,17,45]$. Thus, the sexually dimorphic expression pattern of Posox3 suggests it may play a more important role in ovary than testis in P. olivaceus.

\section{Experimental Section}

\subsection{Animals and Sampling}

P. olivaceus (Pleuronectiformes) individuals used in this study were collected in a commercial fish farm in Haiyang, China. Animal experiments were performed according to the Regulations for the Administration of Affairs Concerning Experimental Animals (China, 1988). The procedures were also approved by College of Marine Life, Ocean University of China (Qingdao, China). The embryos were observed under a dissecting microscope and divided into different stages. Embryos of certain stages, including unfertilized eggs (UF), 1 cell, 2 cells, 4 cells, 8 cells, 16 cells, 32 cells, multi-cells, morula, high blastula, low blastula, early gastrula, mid-gastrula, late gastrula, neurula, somatic, tail-bud, heart-beating, and hatching stages, and seven larvae and juvenile stages at 1, 5, 11, 15, 20, 25, and 46 days post-hatching ( $\mathrm{dph}$ ), were collected in triplicate using $100 \mu \mathrm{m}$ mesh nylon screen, washed with phosphate buffered saline (PBS) and stored in RNAwait (Solarbio, Beijing, China) for further experiment. Adult individuals were acclimatized in laboratory environment for $48 \mathrm{~h}$ before the sampling, after which six individuals (three males and three females) were randomly selected for the tissue sampling of heart, liver, spleen, kidney, whole brain, intestine, gonads, gill and skeletal muscles. The tissue samples were quick-frozen in liquid nitrogen and then stored at $-80{ }^{\circ} \mathrm{C}$ for further experiment.

\subsection{Total RNA and Genomic DNA Extraction}

Total RNA were extracted from multiple tissues or different developmental stages using TRIzol reagent (Invitrogen, Carlsbad, CA, USA) according to the manufacturer's instructions. DNA contamination was detected by $\beta$-actin primers (spanning different exons, Table 1 , $\beta$-actin-Fw/Rv) and eliminated by DNase I (TaKaRa, Dalian, China). Genomic DNA was extracted from muscle tissues with the phenol-chloroform method. All the extracted RNA and DNA samples were examined by agarose gel electrophoresis and quantified using Nanophotometer Pearl (Implen $\mathrm{GmbH}$, Munich, Germany). 
Table 1. Sequences of the primers used in this study.

\begin{tabular}{|c|c|c|}
\hline Experiment & Primer Name & Primer Sequences $\left(5^{\prime}-3^{\prime}\right)$ \\
\hline \multirow{2}{*}{ DNA detection } & $\beta$-actin-Fw & GAGATGAAGCCCAGAGCAAGAG \\
\hline & $\beta$-actin-Rv & CAGCTGTGGTGGTGAAGGAGTAG \\
\hline \multirow{2}{*}{ Core fragment } & sox3-core-Fw & AGCCGCCTCAATGTATAGCA \\
\hline & sox3-core-Rv & GCGTAACCGTCCATCCTCT \\
\hline \multirow{2}{*}{$5^{\prime}$ RACE PCR } & $5^{\prime}$ RACE-sox3-467 & GTCGGTCAGAAGTTTCCAGTCAG \\
\hline & $5^{\prime} R A C E-s o x 3-327$ & GGTCGCTGGCACTGTTGTTCT \\
\hline \multirow{2}{*}{$3^{\prime}$ RACE PCR } & $3^{\prime}$ RACE-sox3-654 & CAGAGGATGGACGGTTACGC \\
\hline & $3^{\prime} R A C E-s o x 3-827$ & TACACGCAGCAGACCACCAAC \\
\hline \multirow{2}{*}{ Full-length cDNA } & sox3-full-length-Fw & AACATTGAACATGATTACGATTCG \\
\hline & sox3-full-length-Rv & ATCGTACAAATTTATTCAGCATTAG \\
\hline \multirow{2}{*}{ Promoter } & sox3-promoter-Fw & GCCTGTATTTGTAGTCTAAT \\
\hline & sox3-promoter-Rv & TGAGGCGGCTTTAAGTGTT \\
\hline \multirow{2}{*}{ qRT-PCR } & sox3-RT-Fw & AACAACGCAGTGTCGGTGG \\
\hline & sox3-RT-Rv & TGCTGTGATGCTGAGGGTAGG \\
\hline \multirow{2}{*}{ qRT-PCR } & $18 S-R T-F w$ & GGTAACGGGGAATCAGGGT \\
\hline & $18 S-R T-R v$ & TGCCTTCCTTGGATGTGGT \\
\hline \multirow{2}{*}{ qRT-PCR } & $U b c E-R T-F w$ & TTACTGTCCATTTCСССАСТGAC \\
\hline & $U b c E-R T-R v$ & GACCACTGCGACCTCAAGATG \\
\hline \multirow{2}{*}{ ISH } & \multirow{2}{*}{ sox3-ISH-SP6 } & ATTTAGGTGACACTATAGAAGTG \\
\hline & & TACACGCAGCAGACCACCAAC \\
\hline \multirow{2}{*}{ ISH } & \multirow{2}{*}{ sox3-ISH-T7 } & TAATACGACTCACTATAGGGAGA \\
\hline & & AAATACACCAGCСТССТCACG \\
\hline
\end{tabular}

\subsection{Molecular Cloning of the Full Length cDNA and Promoter Sequence of Posox3}

Total RNA of the brain tissues was used to obtain the full-length cDNA of Posox3. Briefly, the first strand cDNA was synthesized from $1 \mu \mathrm{g}$ of RNA using M-MLV reverse transcriptase (RNase $\mathrm{H}-$ ) (TaKaRa) and random primers according to the manufacturer's instructions. A positive fragment (1100 bp) sharing high identities with Epinephelus coioides sox3 and Larimichthys crocea sox3 was found by searching the de novo transcriptome sequencing data of $P$. olivaceus [46]. Primer pair sox3-core- $\mathrm{Fw} / \mathrm{Rv}$ was designed to verify the core fragment and ensure sequence accuracy. The remaining unknown UTRs were obtained by $5^{\prime}$ and $3^{\prime}$ RACE using the SMART ${ }^{\mathrm{TM}}$ RACE cDNA Amplification kit (Clontech, Carlsbad, CA, USA) according to manufacturer's protocol, using the universal primer mix (UPM), gene-specific primers (5' RACE-sox3-467 and 5' RACE-sox3-327) for $5^{\prime}$-end sequence, and the nested universal primer (NUP), gene-specific primers ( $3^{\prime}$ RACE-sox3-654/827) for $3^{\prime}$-end sequence. Specific primers sox3-full-length-Fw/Rv, which flanked the entire ORF, were designed based on the assembled cDNA sequence to obtain the genomic DNA sequence and to confirm the full-length coding sequence.

Based on the $P$. olivaceus genomic data, degenerate primer pair sox3-promoter-Fw $/ \mathrm{Rv}$ was designed to amplify and verify the $2000 \mathrm{bp} 5^{\prime}$ upstream sequence of Posox3. DNA fragments that were in the range of expected PCR product size were excised with a razor blade, purified using the Zymoclean gel-purification kit (Zymo Research, Orange, CA, USA), cloned into a pMD 18-T vector (TaKaRa, Dalian, China) and sequenced.

\subsection{Sequence Analysis}

Analyses of the nucleotide and protein sequences were performed with software Lasergene v7.0 (DNASTAR, Madison, WI, USA) and the National Center for Biotechnology Information [47]. Multiple alignments of amino acid sequences were carried out using the ClustalW2 program [48], 
and the results were applied to the generation of a phylogenetic tree by MEGA 6.06. The conserved domains of deduced PoSox3 were analyzed using the simple modular architecture research tool (SMART) [49] and InterProScan search software [50]. The potential TF binding sites within the $5^{\prime}$ upstream region of Posox 3 were predicted via the online program MatInspector (Matrix Family Library Version 9.2) [51]. Comparison of the $5^{\prime}$-flanking regions of sox3 among different fishes was performed with mVISTA using the alignment program AVID [52] and the MEME Suite 4.10.2 [53].

\subsection{Quantitative Real-Time RT-PCR ( $q R T-P C R$ )}

The cDNA templates for qRT-PCR assays were synthesized using the method described above. Pre-experiment was conducted to confirm the specific cDNA PCR product we tested. qRT-PCR was performed in a $20 \mu \mathrm{L}$ reaction volume with cDNA templates $(5 \mathrm{ng})$, the specific primers (sox3-RT-Fw/Rv, $0.2 \mu \mathrm{M}$ ), $1 \times$ SYBR Premix Ex Taq ${ }^{\mathrm{TM}}$ II (Perfect Real Time, TaKaRa) using Light-Cycler Roche 480 (Roche Applied Science, Mannheim, Germany). Melting curves were generated following each cycle to confirm the specificity of the amplicons. Blank controls (with no template) were always included. The relative expression levels of target gene were calculated through a standard curve for quantitation as we previously described [35]. 18s rRNA and UbcE were employed as reference genes [54,55]. All qRT-PCR assays were performed in triplicate under identical conditions. All primers were listed in Table 1.

\subsection{In Situ Hybridization and Histological Analysis}

For ISH analysis, ovary was fixed in $4 \%$ paraformaldehyde-PBS ( $4 \%$ PFA) overnight at $4{ }^{\circ} \mathrm{C}$, dehydrated using graded methanol and stored in pure methanol at $-20^{\circ} \mathrm{C}$. The same sample used for histological observation was fixed in Bouin's fixative for $24 \mathrm{~h}$ and stored in $70 \%$ ethanol at $4{ }^{\circ} \mathrm{C}$.

ISH analysis of Posox 3 expression in the ovary was carried out using a 594 bp probe (positions, 836-1429) containing partial 3' UTR and the C-terminal coding region of Posox3 (Table 1, sox3-ISH-SP6/T7). Digoxigenin (DIG)-labeled antisense and sense riboprobes were synthesized with DIG RNA Labeling Kit (SP6/T7) according to the manufacturer's instructions (Roche). For histological analysis, sections were stained with hematoxylin and eosin (HE). In brief, ISH and HE staining on paraffin-embedded sections of ovary were performed as previously described [35,56]. The sections were observed and photographed by using a Nikon Eclipse Ti-U microscope (Nikon, Tokyo, Japan).

\subsection{Statistical Analysis}

All data were shown as mean \pm standard error of the mean (SEM). Statistical analyses were performed using one-way analysis of variance (ANOVA) followed by Duncan's test in SPSS 20.0 (IBM, New York, NY, USA). $p<0.05$ indicated statistically significant differences among samples.

\section{Conclusions}

In summary, the present study provides the complete cDNA sequence of sox3 gene in P. olivaceus. By gene structure, sequence comparison and phylogenetic analysis, Posox 3 is shown to be the homolog of mammalian Sox3. Several regulatory motifs are found in the $5^{\prime}$ upstream region, suggesting their potential roles in regulating gene expression and function. In addition, we have surveyed the expression patterns by qRT-PCR and ISH. Posox3 expresses at a steady high level from the blastula stage to the hatching stage during early embryogenesis. Poso 3 is highly expressed in the adult brain and shows sexually dimorphic expression pattern. These results will provide fundamental information for further functional investigation of sox3 in Paralichthys olivaceus.

Supplementary Materials: Supplementary materials can be found at http://www.mdpi.com/1422-0067/ $16 / 11 / 26079 / \mathrm{s} 1$. 
Acknowledgments: This work was supported by the National High-Tech Research and Development Program of China (2012AA10A408) and the National Natural Science Foundation of China (No. 31272646).

Author Contributions: Jinning Gao contributed to the experimental process, data analysis and manuscript writing; Quanqi Zhang and Xubo Wang conceived and designed the experiments; Peizhen Li and Wei Zhang contributed to the experimental process; Zhigang Wang contributed to the acquisitiont of experiment samples; and all authors have read and approved the final manuscript.

Conflicts of Interest: The authors declare no conflict of interest.

\section{References}

1. Bowles, J.; Schepers, G.; Koopman, P. Phylogeny of the SOX family of developmental transcription factors based on sequence and structural indicators. Dev. Biol. 2000, 227, 239-255. [CrossRef] [PubMed]

2. Rogers, C.D.; Harafuji, N.; Archer, T.; Cunningham, D.D.; Casey, E.S. Xenopus Sox3 activates Sox2 and geminin and indirectly represses $\mathrm{Xvent} 2$ expression to induce neural progenitor formation at the expense of non-neural ectodermal derivatives. Mech. Dev. 2009, 126, 42-55. [CrossRef] [PubMed]

3. Okuda, Y.; Ogura, E.; Kondoh, H.; Kamachi, Y. B1 SOX coordinate cell specification with patterning and morphogenesis in the early zebrafish embryo. PLoS Genet. 2010, 6, e1000936. [CrossRef] [PubMed]

4. Wood, H.B.; Episkopou, V. Comparative expression of the mouse Sox1, Sox2 and Sox3 genes from pre-gastrulation to early somite stages. Mech. Dev. 1999, 86, 197-201. [CrossRef]

5. Elkouris, M.; Balaskas, N.; Poulou, M.; Politis, P.K.; Panayiotou, E.; Malas, S.; Thomaidou, D.; Remboutsika, E. Sox1 maintains the undifferentiated state of cortical neural progenitor cells via the suppression of prox1-mediated cell cycle exit and neurogenesis. Stem Cells 2011, 29, 89-98. [CrossRef] [PubMed]

6. Graham, V.; Khudyakov, J.; Ellis, P.; Pevny, L. Sox2 functions to maintain neural progenitor identity. Neuron 2003, 39, 749-765. [CrossRef]

7. Wang, T.W.; Stromberg, G.P.; Whitney, J.T.; Brower, N.W.; Klymkowsky, M.W.; Parent, J.M. Sox3 expression identifies neural progenitors in persistent neonatal and adult mouse forebrain germinative zones. J. Comp. Neurol. 2006, 497, 88-100. [CrossRef] [PubMed]

8. Bylund, M.; Andersson, E.; Novitch, B.G.; Muhr, J. Vertebrate neurogenesis is counteracted by Sox1-3 activity. Nat. Neurosci. 2003, 6, 1162-1168. [CrossRef] [PubMed]

9. Avilion, A.A.; Nicolis, S.K.; Pevny, L.H.; Perez, L.; Vivian, N.; Lovell-Badge, R. Multipotent cell lineages in early mouse development depend on SOX2 function. Genes Dev. 2003, 17, 126-140. [CrossRef] [PubMed]

10. Adachi, K.; Suemori, H.; Yasuda, S.Y.; Nakatsuji, N.; Kawase, E. Role of sox2 in maintaining pluripotency of human embryonic stem cells. Genes Cells 2010, 15, 455-470. [PubMed]

11. Kan, L.; Israsena, N.; Zhang, Z.; Hu, M.; Zhao, L.R.; Jalali, A.; Sahni, V.; Kessler, J.A. Sox1 acts through multiple independent pathways to promote neurogenesis. Dev. Biol. 2004, 269, 580-594. [CrossRef] [PubMed]

12. Weiss, J.; Meeks, J.J.; Hurley, L.; Raverot, G.; Frassetto, A.; Jameson, J.L. Sox3 is required for gonadal function, but not sex determination, in males and females. Mol. Cell. Biol. 2003, 23, 8084-8091. [CrossRef] [PubMed]

13. Raverot, G.; Weiss, J.; Park, S.Y.; Hurley, L.; Jameson, J.L. Sox3 expression in undifferentiated spermatogonia is required for the progression of spermatogenesis. Dev. Biol. 2005, 283, 215-225. [CrossRef] [PubMed]

14. Okuda, Y.; Yoda, H.; Uchikawa, M.; Furutani-Seiki, M.; Takeda, H.; Kondoh, H.; Kamachi, Y. Comparative genomic and expression analysis of group B1 sox genes in zebrafish indicates their diversification during vertebrate evolution. Dev. Dyn. 2006, 235, 811-825. [CrossRef] [PubMed]

15. Dee, C.T.; Hirst, C.S.; Shih, Y.H.; Tripathi, V.B.; Patient, R.K.; Scotting, P.J. Sox3 regulates both neural fate and differentiation in the zebrafish ectoderm. Dev. Biol. 2008, 320, 289-301. [CrossRef] [PubMed]

16. Yao, B.; Zhou, L.; Wang, Y.; Xia, W.; Gui, J.F. Differential expression and dynamic changes of SOX3 during gametogenesis and sex reversal in protogynous hermaphroditic fish. J. Exp. Zool. A 2007, 307, 207-219. [CrossRef] [PubMed]

17. Rajakumar, A.; Senthilkumaran, B. Expression analysis of sox3 during testicular development, recrudescence, and after hCG induction in catfish, clarias batrachus. Sex. Dev. 2014, 8, 376-386. [PubMed] 
18. Takehana, Y.; Matsuda, M.; Myosho, T.; Suster, M.L.; Kawakami, K.; Shin, I.T.; Kohara, Y.; Kuroki, Y.; Toyoda, A.; Fujiyama, A.; et al. Co-option of Sox3 as the male-determining factor on the y chromosome in the fish Oryzias dancena. Nat. Commun. 2014, 5, 4157. [CrossRef] [PubMed]

19. Kovacevic Grujicic, N.; Mojsin, M.; Krstic, A.; Stevanovic, M. Functional characterization of the human SOX3 promoter: Identification of transcription factors implicated in basal promoter activity. Gene 2005, 344, 287-297. [CrossRef] [PubMed]

20. Krstic, A.; Mojsin, M.; Stevanovic, M. Regulation of SOX3 gene expression is driven by multiple NF-y binding elements. Arch. Biochem. Biophys. 2007, 467, 163-173. [CrossRef] [PubMed]

21. Mojsin, M.; Popovic, J.; Kovacevic Grujicic, N.; Stevanovic, M. Tg-interacting factor (TGIF) downregulates SOX3 gene expression in the NT2/D1 cell line. J. Genet. Genom. 2012, 39, 19-27. [CrossRef] [PubMed]

22. Kovacevic-Grujicic, N.; Mojsin, M.; Popovic, J.; Petrovic, I.; Topalovic, V.; Stevanovic, M. Cyclic AMP response element binding (CREB) protein acts as a positive regulator of SOX3 gene expression in NT2/D1 cells. BMB Rep. 2014, 47, 197-202. [CrossRef] [PubMed]

23. Mojsin, M.; Stevanovic, M. PBX1 and MEIS1 up-regulate SOX3 gene expression by direct interaction with a consensus binding site within the basal promoter region. Biochem. J. 2010, 425, 107-116. [CrossRef] [PubMed]

24. Savare, J.; Bonneaud, N.; Girard, F. SUMO represses transcriptional activity of the drosophila soxneuro and human sox3 central nervous system-specific transcription factors. Mol. Biol. Cell 2005, 16, 2660-2669. [CrossRef] [PubMed]

25. Gao, J.; Wang, Z.; Shao, K.; Fan, L.; Yang, L.; Song, H.; Liu, M.; Wang, Z.; Wang, X.; Zhang, Q. Identification and characterization of a Sox2 homolog in the japanese flounder paralichthys olivaceus. Gene 2014, 544, 165-176. [CrossRef] [PubMed]

26. Gao, J.; Zhang, W.; Li, P.; Liu, J.; Song, H.; Wang, X.; Zhang, Q. Identification, molecular characterization and gene expression analysis of sox $1 \mathrm{a}$ and sox $1 \mathrm{~b}$ gene in japanese flounder, paralichthys olivaceus. Gene 2015, 574, 225-234. [CrossRef] [PubMed]

27. Kovacevic-Grujicic, N.; Mojsin, M.; Djurovic, J.; Petrovic, I.; Stevanovic, M. Comparison of promoter regions of SOX3, SOX14 and SOX18 orthologs in mammals. DNA Seq. 2008, 19, 185-194. [CrossRef] [PubMed]

28. Ensembl. Available online: http://asia.ensembl.org/index.html. (assessed on 26 August 2015).

29. Stevanovic, M.; Lovell-Badge, R.; Collignon, J.; Goodfellow, P.N. Sox3 is an x-linked gene related to sry. Hum. Mol. Genet. 1993, 2, 2013-2018. [CrossRef] [PubMed]

30. Koyano, S.; Ito, M.; Takamatsu, N.; Takiguchi, S.; Shiba, T. The xenopussox3 gene expressed in oocytes of early stages. Gene 1997, 188, 101-107. [CrossRef]

31. Wiebe, M.S.; Nowling, T.K.; Rizzino, A. Identification of novel domains within Sox-2 and Sox-11 involved in autoinhibition of DNA binding and partnership specificity. J. Biol. Chem. 2003, 278, 17901-17911. [CrossRef] [PubMed]

32. Aota, S.; Nakajima, N.; Sakamoto, R.; Watanabe, S.; Ibaraki, N.; Okazaki, K. Pax6 autoregulation mediated by direct interaction of Pax6 protein with the head surface ectoderm-specific enhancer of the mouse Pax6 gene. Dev. Biol. 2003, 257, 1-13. [CrossRef]

33. Frankenberg, S.; Pask, A.; Renfree, M.B. The evolution of class V POU domain transcription factors in vertebrates and their characterisation in a marsupial. Dev. Biol. 2010, 337, 162-170. [CrossRef] [PubMed]

34. McAninch, D.; Thomas, P. Identification of highly conserved putative developmental enhancers bound by SOX3 in neural progenitors using CHIP-Seq. PLOS ONE 2014, 9, e113361. [CrossRef] [PubMed]

35. Gao, J.; Wang, J.; Jiang, J.; Fan, L.; Wang, W.; Liu, J.; Zhang, Q.; Wang, X. Identification and characterization of a nanog homolog in japanese flounder (paralichthys olivaceus). Gene 2013, 531, 411-421. [CrossRef] [PubMed]

36. Weirauch, M.T.; Hughes, T.R. Conserved expression without conserved regulatory sequence: The more things change, the more they stay the same. Trends Genet. 2010, 26, 66-74. [CrossRef] [PubMed]

37. Archer, T.C.; Jin, J.; Casey, E.S. Interaction of Sox1, Sox2, Sox3 and Oct4 during primary neurogenesis. Dev. Biol. 2011, 350, 429-440. [CrossRef] [PubMed]

38. Djurovic, J.; Stevanovic, M. Structural and functional characterization of the human SOX14 promoter. Biochim. Biophys. Acta 2004, 1680, 53-59. [CrossRef] [PubMed]

39. Bo, Y.; Li, Z.; Jianfang, G. Studies on cDNA cloning and temporal and spatial expression of sox3 gene in grouper epinephelus coioides. High Technol. Lett. 2003, 13, 74-81. 
40. Wagner, J.T.; Podrabsky, J.E. Gene expression patterns that support novel developmental stress buffering in embryos of the annual killifish austrofundulus limnaeus. Evo Devo 2015, 6, 2. [CrossRef] [PubMed]

41. Rogers, C.D.; Archer, T.C.; Cunningham, D.D.; Grammer, T.C.; Casey, E.M. Sox3 expression is maintained by FGF signaling and restricted to the neural plate by vent proteins in the xenopus embryo. Dev. Biol. 2008, 313, 307-319. [CrossRef] [PubMed]

42. Uwanogho, D.; Rex, M.; Cartwright, E.J.; Pearl, G.; Healy, C.; Scotting, P.J.; Sharpe, P.T. Embryonic expression of the chicken sox2, sox3 and soxll suggests an interactive role in neuronal development. Mech. Dev. 1995, 49, 23-36. [CrossRef]

43. Rizzoti, K.; Brunelli, S.; Carmignac, D.; Thomas, P.Q.; Robinson, I.C.; Lovell-Badge, R. Sox3 is required during the formation of the hypothalamo-pituitary axis. Nat. Genet. 2004, 36, 247-255. [CrossRef] [PubMed]

44. Temple, S. The development of neural stem cells. Nature 2001, 414, 112-117. [CrossRef] [PubMed]

45. Shin, H.S.; An, K.W.; Park, M.S.; Jeong, M.H.; Choi, C.Y. Quantitative mRNA expression of sox3 and DMRT1 during sex reversal, and expression profiles after GnRHa administration in black porgy, acanthopagrus schlegeli. Comp. Biochem. Physiol. B 2009, 154, 150-156. [CrossRef] [PubMed]

46. Wang, W.; Wang, J.; You, F.; Ma, L.; Yang, X.; Gao, J.; He, Y.; Qi, J.; Yu, H.; Wang, Z.; et al. Detection of alternative splice and gene duplication by RNA sequencing in japanese flounder, paralichthys olivaceus. Gene Genom. Genet. 2014, 4, 2419-2424. [CrossRef] [PubMed]

47. National Center for Biotechnology Information. Available online: http://www.ncbi.nlm.gov (accessed on 26 August 2015).

48. ClustalW2. Available online: http://www.ebi.ac.uk/tools/msa/clustalw2/ (accessed on 26 August 2015).

49. Simple Modular Architecture Research Tool. Available online: http://smart.embl-heidelberg.de/ (accessed on 26 August 2015).

50. Interproscan. Available online: http://www.ebi.ac.uk/tools/pfa/iprscan/ (accessed on 26 August 2015).

51. Matinspector. Available online: http://www.genomatix.de/matinspector.html (assessed on 26 August 2015).

52. mVISTA. Available online: http://genome.Lbl.Gov/vista/mvista/submit.shtml (assessed on 26 August 2015).

53. Meme Suite. Available online: http://meme-suite.org/tools/meme (assessed on 26 August 2015).

54. Zhong, Q.; Zhang, Q.; Wang, Z.; Qi, J.; Chen, Y.; Li, S.; Sun, Y.; Li, C.; Lan, X. Expression profiling and validation of potential reference genes during paralichthys olivaceus embryogenesis. Mar. Biotechnol. 2008, 10, 310-318. [CrossRef] [PubMed]

55. Zhang, J.; Hu, Y.H.; Sun, B.G.; Xiao, Z.Z.; Sun, L. Selection of normalization factors for quantitative real time RT-PCR studies in japanese flounder (paralichthys olivaceus) and turbot (scophthalmus maximus) under conditions of viral infection. Vet. Immunol. Immunopathol. 2013, 152, 303-316. [CrossRef] [PubMed]

56. Feng, Z.-F.; Zhang, Z.-F.; Shao, M.-Y.; Zhu, W. Developmental expression pattern of the Fc-vasa-like gene, gonadogenesis and development of germ cell in chinese shrimp, fenneropenaeus chinensis. Aquaculture 2011, 314, 202-209. [CrossRef]

(C) 2015 by the authors; licensee MDPI, Basel, Switzerland. This article is an open access article distributed under the terms and conditions of the Creative Commons by Attribution (CC-BY) license (http://creativecommons.org/licenses/by/4.0/). 